\title{
Numerical Modeling of High Conversion Efficiency Mo/CZTS/CdS/ZnO/ FTO Thin Film - Based Solar Cells
}

\section{Samer H. Zyoud ${ }^{1,2,3, \text { a }^{*} \text {, Ahed H. Zyoud }}{ }^{4, b}$, Naser M. Ahmed ${ }^{\text {3, c }}$, Anupama R. Prasad ${ }^{\text {5, d, }}$ Sohaib Naseem Khan ${ }^{6,7, \text { e, Atef AbdelKader }}{ }^{1,2, \text { f , and Moayed J. Shahwan }}{ }^{6,7, \mathrm{~g}}$}

${ }^{1}$ Department of Mathematics and Sciences, Ajman University, Ajman, United Arab Emirates ${ }^{2}$ Nonlinear Dynamics Research Center (NDRC), Ajman University, Ajman, United Arab Emirates

${ }^{3}$ School of Physics, Universiti Sains Malaysia, 11800, USM Penang, Malaysia

${ }^{4}$ Department of Chemistry, An-Najah National University, Nablus, Palestine

${ }^{5}$ Department of Chemistry, University of Calicut, Calicut University P O, Kerala, India

${ }^{6}$ College of Pharmacy \& Health Sciences, Ajman University, Ajman, United Arab Emirates

${ }^{7}$ Centre of Medical and Bio-Allied Health Sciences Research, Ajman University, Ajman, United Arab Emirates

年.zyoud@ajman.ac.ae, ${ }^{b}$ ahedzyoud@najah.edu, ${ }^{c}$ naser@usm.my, danuprar@gmail.com.

esohaib.khan@ajman.ac.ae, ${ }^{\mathrm{f}}$ a.abdelkader@ajman.ac.ae, ${ }^{\mathrm{g}} \mathrm{m}$. shahwan@ajman.ac.ae

\begin{abstract}
This article describes in detail the numerical modeling of a CZTS (copper zinc tin sulfide) based kesterite solar cell. The Solar Cell Capacitance Simulator -one-dimension (SCAPS-1D) software was used to simulate MO/CZTS/CdS/ZnO/FTO structured solar cells. The parameters of different photovoltaic thin-film solar cells are estimated and analyzed using numerical modeling. The effects of various parameters on the performance of the photovoltaic cell and the conversion efficiency are discussed. Since the response of the solar cell is also contingent on its internal physical mechanism, $J-V$ characteristic measures are insufficient to characterize the behavior of a device. Different features, as well as different potential conditions, must be considered for simulation, disregarding the belief in the modeling of a solar cell. With a conversion efficiency of $25.72 \%$, a fill factor of $83.75 \%$, a shortcircuit current of $32.96436 \mathrm{~mA} / \mathrm{cm}^{2}$ and an open-circuit voltage of $0.64 \mathrm{~V}$, promising optimized results have been achieved. The findings will be useful in determining the feasibility of fabricating high-efficiency CZTS-based photovoltaic cells. The efficiency of a CZTS-based experimental solar cell is also discussed. First, the effects of experimentally developed CZTS solar cells are simulated in the SCAPS-1D environment. The experimental results are then compared to the SCAPS-1D simulated results. The conversion efficiency of an optimized system increases after cell parameters are optimized. Using one-dimensional SCAPS-1D software, the effect of system parameters such as the thickness, acceptor and donor carrier concentration densities of absorber and electron transport layers, and the effect of temperature on the efficiency of CZTS-based photovoltaic cells is investigated. The proposed results will greatly assist engineers and researchers in determining the best method for optimizing solar cell efficiency, as well as in the development of efficient CZTS-based solar cells.
\end{abstract}

Keywords: Absorber Layer, Buffer Layer, CZTS, CdSe, ZnSe, Conversion Efficiency, Carrier Concentration, Temperature, SCAPS-1D, Solar Cell. 


\subsection{Introduction}

Solar cells have emerged as a more recent and relatively renewable energy source that is both ecofriendly and cost-effective when produced on a larger scale. In the current scenario, photovoltaic devices with high power conversion efficiency and no material degradation are being developed for the generation of electricity [1]. For several years, silicon-based solar cells dominated the market. Advanced fabrication techniques are required for the manufacturing and production of silicon-based solar cells, which makes the solar panel expensive [2]. Thin film solar cells are becoming more popular as manufacturing capabilities improve. Thin film technology is one of the most cost-effective and efficient methods of producing solar cells, and it is a hot topic of research in the photovoltaic industry. Thin film technology is more cost-effective than other technologies because it uses less material and is based on a range of light-absorbing semiconductor materials [3]. Among these materials, Kesterite solar cells utilizing copper zinc tin sulfide $\mathrm{Cu} 2 \mathrm{ZnSnS} 4$ (CZTS) and their alloys are a promising alternative for the chalcopyrite absorbers [4-6]. These excellent optical and electrical properties with an optical band gap from $1.4 \mathrm{eV}$ to $1.5 \mathrm{eV}$ along with a large absorption coefficient of $\left(\alpha>104 \mathrm{~cm}^{-1}\right)$ of the CZTS has made it an interesting insight for the community of thin film [7]. By tuning the band gap, a CZTS-based solar cell can theoretically achieve an optimum conversion efficiency of around $28 \%$, according to the Shockley-Queisser limit. However, due to a lack of understanding of device characteristics, it is not experimentally possible to achieve 28 percent conversion efficiency from a solar cell [8]. Numerical modelling can play a major part in a deeper understanding of system characteristics by modelling various device architectures, which can save time and money for the research community. In this work, computational modeling was carried out for estimating and analyzing the effect of physical parameters such as thickness and doping concentration of absorber, buffer and window layers and temperature effect on system output. The simulation program "Solar Cell Capacitance Simulator" was used to model the unit (SCAPS-1D). To begin, a simple heterostructure for CZTS/ CdS/ ZnO thin films with molybdenum (Mo) as the back contact and indium tin oxide (ITO) as the front contact was analyzed. Variations in absorber thickness, doping concentration, and working temperature were found to affect solar cell performance through analysis. First, the effects of experimentally developed CZTS solar cells were simulated in the SCAPS-1D environment. The experimental results were then compared to the SCAPS-1D simulated results. The main goals and objectives of this research are to use computational modelling to improve the performance of thin 
film solar cells, to suggest new ways to improve the efficiency of experimental solar cells, and to find alternative methods to reduce the cost of thin film solar cells. The effects of the thickness, doping concentration, and working temperature of the absorber, buffer, and window layers, as well as the working temperature, were investigated to analyze their effect on the cell performance.

\subsection{Numerical Modeling and Material Parameters}

Numerical modeling is a methodology for evaluating system behavior using complex mathematical models and assisting in the production of analytical solutions. In the manufacturing and fabrication of efficiently operating semiconductor-based photovoltaic modules, numerical analysis can be very useful. Because of seeking the most optimal and effective ways to solve a complex problem, the integration of real-life problems with virtual machine environments is the highest priority task of numerical modeling techniques implementation for design engineers and researchers [9]. Since real-world design problems can be solved in computer-based testing environments without needing physical or functional implementation, academic institutions and universities emphasize computer-based learning techniques. Modeling methods are used to calculate fundamental physical properties including the concentration of holes and electrons, as well as the electrical potential. It also offers more information about how material physical parameters impact system functional parameters or characteristics. Physical material parameters are used as input to simulation software for numerical modeling of solar cells [10]. Experimental data is needed to convert the real or actual device $\mathrm{J}-\mathrm{V}$ characteristics and functional parameters such as quantum conversion performance, fill factor, open circuit voltage, and short circuit current into device modeling. Numerical simulation allows for a deeper and more straightforward understanding of system behavior. The simulation software that can be used for device modeling must be able to solve semiconductor basic equations like the continuity equation for holes and electrons and the Poisson equation relating charge to electrostatic potential to gain a better understanding of a device's output.

\subsection{Numerical Modeling}

The electrons and holes move in opposite directions is the main cause of current flow. The number of electrons and holes are equal. Hole mobility $\mu_{\mathrm{p}}$ is practically half of the electron mobility $\mu_{e}$ [11]. The overall flow of current density $(J)$ is due to electron and hole flow is given by "Eq.1" 
$J=n_{i} e\left(\mu_{e}+\mu_{p}\right) E$

$\mu_{e}$ and $\mu_{p}$ are the electron and hole mobilities $\left(\mathrm{cm}^{2} / \mathrm{Vs}\right), n_{i}$ and $p_{i}$ are free electrons densities in an intrinsic semiconductor $\left(\mathrm{cm}^{-3}\right), e$ is the elementary charge $\left(1.6 \times 10^{-19} \mathrm{C}\right)$, and $E$ is the applied electric field $(\mathrm{V} / \mathrm{m})$. The conductivity of semiconductor depends on current carriers and the number of current carriers presented per unit volume. From the above equation with an increase in temperature, $n_{i}$ and $p_{i}$ increases and the conductivity of intrinsic semiconductor increases, which means resistivity decreases. Shockley's equation explains the general characteristics of forward and reverse biasing regions of diode [12]. The diode current equation is given in "Eq.2":

$I=I_{o}\left(e^{\frac{q V_{D}}{n k T}}-1\right)$

Where $I$ is diode current, $I_{o}$ is reverse saturation current, $V_{D}$ is diode voltage, $n$ is ideality factor, $k$ is Boltzmann's constant $\left(1.38 \times 10^{-2} \mathrm{~J} / K\right)$, and $T$ is absolute temperature $(\mathrm{K})$. The maximum current flow through the solar cell at zero load condition $\left(a t R_{L}=0\right)$ or short-circuit current $\left(I_{s c}\right)$ at the voltage of a solar cell will be zero [13]. The flow of $I_{s c}$ is due to the collection and generation of light generated carriers. It mainly depends on the number of incident photons as well as the spectrum, area of solar cell, optical properties and the collection probability of light generated carriers. The short current density $\left(\mathrm{J}_{\mathrm{sc}}\right)$ can be found by Eq. (3) [14]:

$$
J_{S C}=q \sum T(\lambda) \frac{\phi_{i}\left(\lambda_{i}\right)}{h v_{i}} \eta\left(\lambda_{i}\right) \Delta \lambda_{i}
$$

Where $q$ is the elementary charge, $T(\lambda)$ is the optical transmission, $\emptyset_{i}$ is the spectral power density, and $\Delta \lambda_{i}$ is the interval between the two neighboring values of wavelength. The maximum voltage is taken from the solar cell $\left(a t R_{L}=\infty\right)$ is known as open circuit voltage $\left(V_{O C}\right)$. When a solar cell is an open circuited, and no load is connected across the solar cell then current will be at its minimum (zero) value whereas the voltage will be at maximum value [15]. The open-circuit voltage ( $\left.V_{O C}\right)$, can be expressed by "Eq. 4" [16]:

$V_{O C}=\frac{n k T}{q} \ln \left(\frac{\mathrm{I}_{L}}{I_{O}}+1\right)$ 
From the above equation, it is clear that open circuit voltage depends on $I_{o}$ (saturation current) and $I_{L}$ (light generated current). $I_{O}$ depends on recombination in the solar cell. So, $V_{O C}$ is a measure of the amount of recombination in a solar cell. The measure of a photovoltaic cell quality is fill factor $(F F)$, which is derived by equating the maximum power $(P \max )$ to the theoretical power $(P t)$. Where power $\left(P_{t}\right)$ would be output at both the open circuit voltage $\left(V_{O C}\right)$ and short-circuit current density $\left(J_{s c}\right)$ as given in "Eq. 5"

$F F=\frac{V_{\max } I_{\max }}{V_{o c} I_{S C}}$ (Eq. 5)

Energy conversion efficiency is the most frequently used parameter to relate the performance of two solar cells and is termed as $\eta$. It is defined as the ratio of output power from a solar cell to the input power from the sun [15]. The energy conversion efficiency can be expressed by "Eq. 6"[16] $\eta=\frac{V_{O C} \times J_{S C} \times F F}{P_{\text {in }}}$

The efficiency, $\eta$ depends on the parameters like incident sunlight intensity, solar cell working temperature and spectrum type. So, to compare two or more solar cells, it is important to carefully control the conditions under which $\eta$ is measured. The incident light (photons) illumination is AM1.5G spectra through the calculation of the $\mathrm{J}-\mathrm{V}$ characteristics in this numerical simulation analysis [17] The input power, $P_{i n}$, from the sun is considered as $1000 \mathrm{~W} / \mathrm{m}^{2}$, and its properties are summarized in Table (2). The quantum efficiency $(Q E)$ is the ratio of the extracted free charge carriers by the solar cell to the number of incident photons. In other words, $Q E$ relates to the response of a solar cell to different wavelengths. It may be given either as a function of energy or wavelength. The $Q E$ will be unity at the precise wavelength if all certain wavelength photons are absorbed and the resulting minority carriers are collected. The spectral response was evaluated based on the quantum efficiency measurements; the QE is defined according to the following Eq. (7) $[18]$ :

$Q E(\lambda)=\frac{I(\lambda) / q}{\varphi_{p}(\lambda)}$

Where $q$ is the elementary electrical charge, $I(\lambda)$ is photogenerated current $\varphi_{p}(\lambda)$ is photon flow. Solar Cell Capacitance Simulator (SCAPS) program developed at the University of Gent, Belgium is used to simulate the photovoltaic devices. Several researchers have contributed to its development. SCAPS- 1D is the one-dimensional simulation program for the modeling of PV 
devices. Seven different semiconductor layers exclusive of back and front contacts are possible to take as input in SCAPS- 1D software. SCAPS- 1D tool is freely available for the photovoltaic research community and can be freely downloaded from its web link. It runs on a window operating system environment. This software is designed to simulate and helps us to analyze the $J-V$ characteristics curve, ac characteristics $(C-V$ and $C-f)$, spectral response $(Q E)$ of a device, power conversion efficiency $(\eta)$, fill factor $(F F)$, short-circuit current $(J S C)$, open circuit voltage $(V o c)$, energy bands of materials used in solar cell and concentration of different material used by solving the semiconductor basic equations [19-21]. SCAPS- 1D can solve Poisson and continuity equations for electrons and holes Eq. (8) and (9) [22,23]:

$\frac{d^{2} \Psi}{d x^{2}}=\frac{e}{\epsilon_{o} \epsilon_{r}}\left[P(x)-n(x)+N_{D}-N_{A}+\rho_{P}-\rho_{n}\right]$

Where $\Psi$ is electrostatic potential, $e$ is elementary electrical charge, $\epsilon_{r}, \varepsilon_{o}$ are relative and vacuum permittivity, $p$ and $n$ are hole and electron concentrations, $N_{D}, N_{A}$ are charged impurities of donor and acceptor, $\rho_{p}$ and $\rho_{n}$ are holes and electrons distribution, respectively.

$\frac{d J_{n}}{d x}=\frac{d J_{p}}{d x}=G-R$

Where $J_{n}$ and $J_{p}$ are electron and hole current densities, $R$ is the recombination rate, and $G$ is the generation rate. Carrier transport occurs by drift and diffusion according to Eq. (10) and Eq. (11), respectively:

$J_{n}=D_{n} \frac{d n}{d x}+\mu_{n} n \frac{d \varphi}{d x}$

$J_{p}=D_{p} \frac{d p}{d x}+\mu_{p} p \frac{d \varphi}{d x}$

\subsection{The thin-film solar cell device}

The thin-film solar cell device was constructed by glass substrate as a back-supporting slide, molybdenum (Mo) thin layer film was deposited on the glass substrate layer, CZTST (p-type) layer with a thickness of (1200 -3600 nm) was deposited on Molybdenum that is coated the back of substrate glass. The CdS (n-type) used as a buffer layer with a thickness of (10-100 nm), ZnO layer (n-type) with a thickness of (40-280 nm) was used as a window and FTO with a thickness (280 $\mathrm{nm}$ ) was used as transparent conducting oxides (TCO). The materials for the modeling device were chosen for their efficiency, stability, low cost, and ease of preparation. The illustration for the 
modeling layers layout is shown in Fig. 1. These essential components of a device are utilized to determine a solar cell's electrical and photoelectric properties.

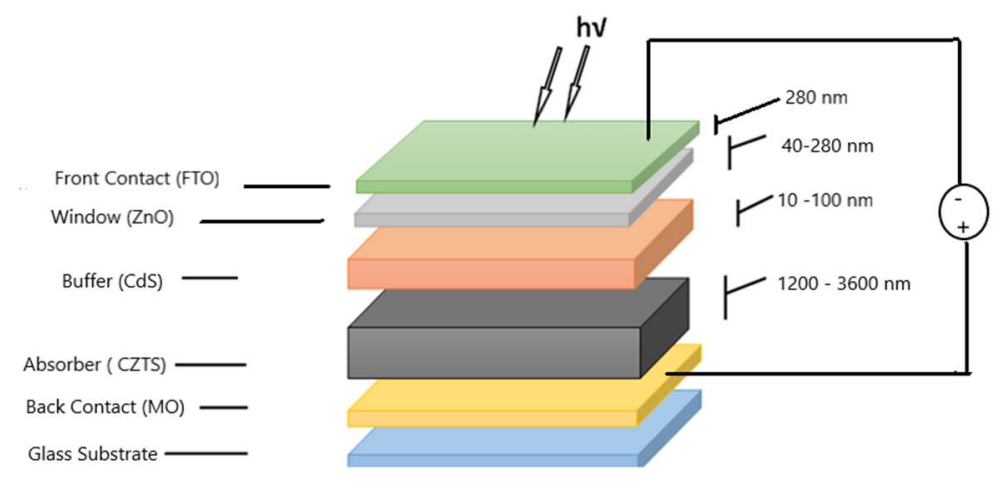

Figure 1. Schematic diagram of thin film

\subsection{Material Parameters}

In order to solve the basic semiconductor equations, input parameters, also known as physical parameters, are required. Layer thickness, electron-hole mobility, intrinsic carrier concentration, electron affinity, band gap and doping density of absorber, buffer, and window layers, among other physical characteristics utilized in SCAPS 1D software for numerical analysis, are mentioned in "Table 1." All simulations are run with 1.5AM solar radiation and a power density of $100 \mathrm{~mW} / \mathrm{cm}^{2}$ for the lighting source. "Table 2" lists the functional properties of solar cells. The qualities of the back and front contact parameters are provided in "Table 3." The device's construction has two goals in common. The first is analyzing and verifying real-world device behavior, and the second involves simulating a device for certain physical parameters and predicting the results. The behavior of the reference device (s) was effectively simulated, which defines successful device modeling. Physical or input parameters are obtained from referenced device experimental data to create device modeling. Batch simulations are used to monitor and assess predefined physical parameters such as carrier concentration densities and layer thickness. The SCAPS-1D program outputs the J-V characteristics curve, band alignment diagram, spectral response, and other functional parameters including $V_{O C}, J_{S C}, F F$, and $\eta$, which are highly useful for fabricating an efficient photovoltaic device. All measurements are made in both lit and dark circumstances, as well as a function of temperature. Thermal velocity and effective density of states are temperaturedependent quantities, whereas band gap and mobility are temperature-independent parameters. 
Table 1. Simulation parameters for modeling of CZTS based kesterite solar cell. [24-26]

\begin{tabular}{lllll}
\hline Parameter & p-CZTS & n- CdS & n-ZnO & FTO \\
\hline $\mathrm{W}(\mathrm{nm})$ & $1200-3600$ & $10-100$ & $40-280$ & 280 \\
$\mathrm{E}_{\mathrm{g}}(\mathrm{eV})$ & 1.45 & 2.4 & 3.3 & 3.5 \\
$\chi(\mathrm{eV})$ & 4.5 & 4.5 & 4.6 & 4 \\
$\varepsilon_{\mathrm{r}}$ & 9 & 9 & 9 & 9 \\
$\mathrm{~N}_{\mathrm{C}}\left(\mathrm{cm}^{-3}\right)$ & $2.2 \times 10^{18}$ & $1.8 \times 10^{19}$ & $2.2 \times 10^{18}$ & $1 \times 10^{19}$ \\
$\mathrm{~N}_{\mathrm{V}}\left(\mathrm{cm}^{-3}\right)$ & $1.8 \times 10^{19}$ & $2.4 \times 10^{18}$ & $1.8 \times 10^{19}$ & $1 \times 10^{18}$ \\
$\mathrm{~V}_{\mathrm{e}-\mathrm{th}}(\mathrm{cm} / \mathrm{s})$ & $1 \times 10^{7}$ & $1 \times 10^{7}$ & $1 \times 10^{7}$ & $1 \times 10^{7}$ \\
$\mathrm{~V}_{\mathrm{p}-\mathrm{th}}(\mathrm{cm} / \mathrm{s})$ & $1 \times 10^{7}$ & $1 \times 10^{7}$ & $1 \times 10^{7}$ & $1 \times 10^{7}$ \\
$\mu_{\mathrm{e}}\left(\mathrm{cm}^{2} / \mathrm{Vs}\right)$ & 60 & 100 & 100 & 20 \\
$\mu_{\mathrm{p}}\left(\mathrm{cm}^{2} / \mathrm{Vs}\right)$ & 20 & 25 & 25 & 10 \\
$\mathrm{~N}_{\mathrm{D}}\left(\mathrm{cm}^{-3}\right)$ & 0 & $1 \times 10^{17}-1 \times 10^{18}$ & $1 \times 10^{18}-1 \times 10^{19}$ & $1 \times 10^{18}$ \\
$\mathrm{~N}_{\mathrm{A}}\left(\mathrm{cm}^{-3}\right)$ & $1 \times 10^{16}-1 \times 10^{17}$ & 0 & 0 & 0 \\
\hline
\end{tabular}

W: Thickness, Eg: Band gap, $\chi$ : Electron affinity, Er: Dielectric permittivity (relative), $\mathbf{N}_{\mathbf{C}}$ : Conductance band effective density of states, $\mathbf{N}_{\mathbf{v}}$ : Valance band effective density of states, $\mathbf{V}_{\mathbf{e} \text {-th }}$ : Electron thermal velocity, $\mathbf{V}_{\mathbf{p} \text {-th }}$ : Hole thermal velocity, $\boldsymbol{\mu}_{\mathrm{e}}$ : Electron mobility, $\boldsymbol{\mu}_{\mathrm{p}}$ : Hole mobility, $\mathbf{N}_{\mathbf{D}}$ : Shallow uniform donor density, $\mathbf{N}_{\mathrm{A}}$ : Shallow uniform acceptor density

Table 2: The incident illumination (photons) source parameters.

\begin{tabular}{lc}
\hline Spectrum & AM 1.5G1 sun. Spectrum \\
\hline Wavelength range $(\mathrm{nm})$ & $200-4000$ \\
Transmission\% & 100 \\
Ideal light current $\mathrm{G}(\mathrm{x})\left(\mathrm{mA} / \mathrm{cm}^{2}\right)$ & 20 \\
Transmission of attenuation filter $\%$ & 100 \\
Ideal light current cell $\left(\mathrm{mA} / \mathrm{cm}^{2}\right)$ & 0 \\
\hline
\end{tabular}


Table 3. Back and front contact parameters properties.

\begin{tabular}{llcr}
\hline & & Left Contact (Back) & Right Contact (Front) \\
\hline \multirow{2}{*}{$\begin{array}{l}\text { Thermionic emission surface } \\
\text { recombination velocity (cm/s) }\end{array}$} & Electron & $1 \times 10^{7}$ & $1 \times 10^{7}$ \\
& Moles & $1 \times 10^{7}$ & $1 \times 10^{7}$ \\
\hline \multirow{2}{*}{ Majority carrier barrier height $(\mathrm{eV})$} & Relative to EF & 4.6 & 4.1 \\
\hline
\end{tabular}

\subsection{Results and Discussion}

\subsection{Effect of layers thickness on the device performance}

\subsubsection{Effect of CZTS absorber (acceptor) layer thickness on the device performance}

The major objective of this section is to create a thinner CdTe layer without sacrificing device performance. As a result, the cost of manufacturing solar cells may be reduced by reducing the amount of materials used in the process. The thickness of a device's absorber layer has a direct impact on conversion efficiency $(\eta)$. "Table 4" and "Fig. 2(a)" indicate the influence of absorber layer (CZTS) thickness on solar cell performance. The effect of altering the thickness of the CZTS absorber layer from $1200 \mathrm{~nm}$ to $3600 \mathrm{~nm}$ on the effect of other material properties of different layers was investigated. When the thickness of an absorber layer is increased, $J_{S C}$ rises in tandem with the increase in $V_{O C}$. The conversion efficiency rises up to a steady-state thickness of 2400 $\mathrm{nm}$, whereas FF declines to a point where the ideal thickness is obtained. The conversion efficiency $(\eta)$ will remain constant once the ideal settings are reached. Furthermore, increasing the thickness reduces the $F F$. The rise in $J_{S C}$ with increased $V_{O C}$, is mostly due to increased absorption of longer wavelength photons, which affects the ration of photogenerated carriers. The thickness of the absorber layer that was chosen as the best was $2400 \mathrm{~nm}$. However, one of the major issues with today's large-scale and mass-production CZTS solar cells is the thickness of the absorber layer. The emission of electron-hole pairs is influenced by the wavelengths of the light. The thickness of the CdTe layer is responsible for these changes since a larger CZTS layer may absorb more photons across a wider wavelength range. Fig 2 (b) shows the influence of CZTS thickness on QE\%. The QE\% was estimated for a variety of CdTe thicknesses ranging from 1200 to $3600 \mathrm{~nm}$. The QE\% rose when the CZTS layer thickness was raised. 
The layer thickness of more than $2400 \mathrm{~nm}$ has no significant effect on the pace of QE\% increases. This suggests that a thickness of $2400 \mathrm{~nm}$ is sufficient to absorb the vast majority of incoming photons. Because the generation zone in thinner CdTe layer cells is close to the high recombination back contact region, the quantity of created electron-hole pairs will be reduced, lowering the quantum efficiency. The generating mechanism happens distant from the rear in thicker CdTe layer cells. Finally, modeling findings indicate that the optimal thickness of the CdTe absorber layer is $2400 \mathrm{~nm}$, with a percent of $23.02 \%$.

Table 4: The effect of absorber (CZTS) layer thickness on cell efficiency parameter CdS, ZnO and ITO layer thicknesses are 100 $\mathrm{nm}, 200 \mathrm{~nm}$, and $280 \mathrm{~nm}$ respectively, $T=300 \mathrm{~K}$

\begin{tabular}{lllll}
\hline Thickness (nm) & $\mathbf{V}_{\mathbf{O C}}(\mathbf{V})$ & $\mathbf{J}_{\mathbf{S C}}\left(\mathbf{m A} \mathbf{\mathbf { c m } ^ { 2 }}\right)$ & $\mathbf{F F}$ & $\boldsymbol{\eta}$ \\
\hline 1200 & 0.8662 & 29.196593 & 82.46 & 20.85 \\
1600 & 0.8768 & 30.175689 & 82.86 & 21.92 \\
2000 & 0.8851 & 30.788066 & 82.89 & 22.59 \\
2400 & 0.8921 & 31.188947 & 82.73 & 23.02 \\
2800 & 0.8983 & 31.457338 & 82.46 & 23.3 \\
3200 & 0.9040 & 31.638435 & 82.14 & 23.49 \\
3600 & 0.909 & 31.761007 & 81.82 & 23.62 \\
\hline
\end{tabular}
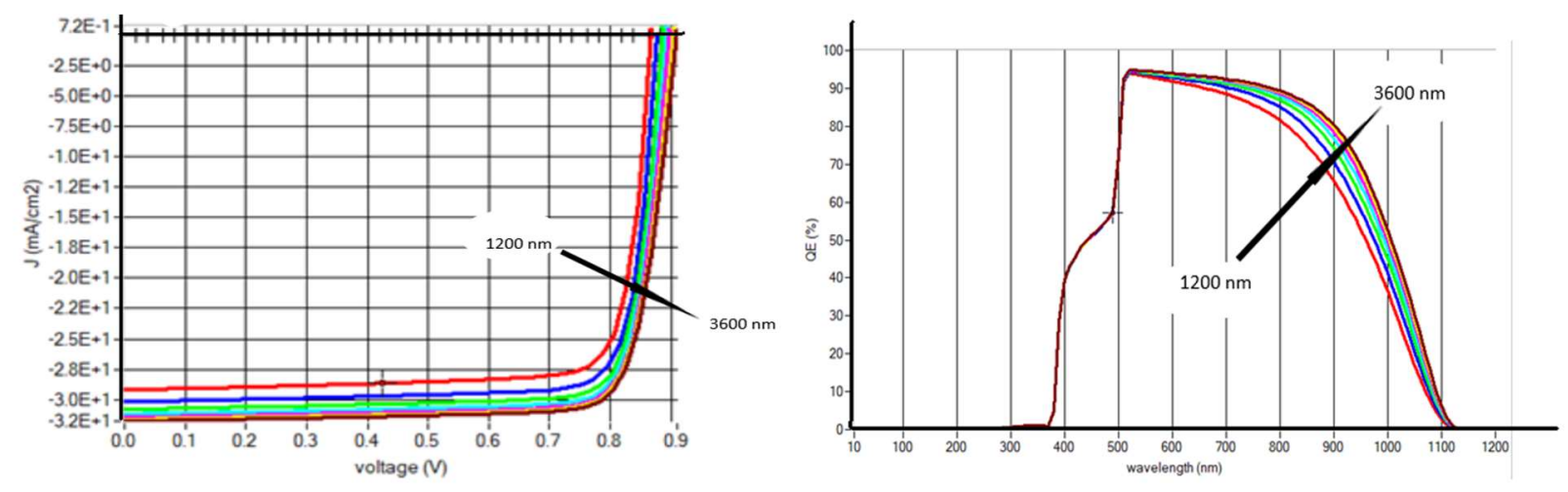

Figure 2. (a) J -V current curves, (b) Quantum efficiency percentage (QE\%) for the cell at different thickness CZTS layer, CdS, $\mathrm{ZnO}$ and ITO layer thicknesses are $100 \mathrm{~nm}, 200 \mathrm{~nm}$, and $280 \mathrm{~nm}$ respectively, $T=300 \mathrm{~K}$

\subsubsection{Effect of CdS buffer (donor) layer thickness on the device performance}

The effect of buffer layer thickness on solar cell performance is also investigated. One of the major goals of this simulation is to decrease the optical and electrical losses induced by the buffer layer in incoming radiation. The thickness of the buffer $(\mathrm{CdS})$ layer was changed from $10 \mathrm{~nm}$ to 100 nm. "Table 5" and "Fig. 3 (a)" illustrate simulated outcomes. 
Table 5. shows that increasing the thickness of the buffer layer has limited effect on $V_{O C}, J_{S C}, F F$, and $\eta$. As a consequence, it was concluded that changing the thickness of the buffer layer had no effect on the output of a photovoltaic device. The results demonstrated that when the thickness of the CdS layer increases, the cell performance declines. CdS thickness has a greater impact on Jsc and percent values than it does on $F F$ and $V_{O C}$. The photon losses that occur in a thicker CdS layer are responsible for the non-significant influence on $V_{O C}$ and $F F$. The thicker CdS buffer layer absorbs more photons from input radiation, limiting the number of photons that reach the absorption (CZTS) layer and, as a result, lowering the QE percent, as shown in "Fig.3(b)". As a result, the number of produced electron-hole pairs will be reduced. In the thicker CdS films, the Jsc and percent values were found to be much lower. The thinner CdS layer, on the other hand, has a greater performance efficiency because the depletion layer thickness is reduced in the narrower CdS layer. The depletion layer appears to compensate for the impact of misfit dislocation caused by the CdS and CZTS layers' lattice mismatch. A leakage current is caused by the smaller buffer layer, whereas a poor carrier separation rate is caused by the thicker one. Due to limitations in manufacturing procedures and tools, layer thicknesses of less than $25 \mathrm{~nm}$ are not possible. As a result, the optimum and recommended buffer layer must be at least $25 \mathrm{~nm}$ thick.

Table 5: The effect of buffer (CdS) layer thickness on cell efficiency parameter, CZTS, ZnO and ITO layer thicknesses are $2400 \mathrm{~nm}$, $200 \mathrm{~nm}$, and $280 \mathrm{~nm}$ respectively, $T=300 \mathrm{~K}$

\begin{tabular}{lllll}
\hline Thickness $(\mathbf{n m})$ & $\mathbf{V}_{\mathbf{O C}}(\mathbf{V})$ & $\mathbf{J}_{\mathbf{S C}}\left(\mathbf{m A} \mathbf{\mathbf { c }} \mathbf{c m}^{\mathbf{2}}\right)$ & $\mathbf{F F}$ & $\boldsymbol{\eta}$ \\
\hline 10 & 0.8925 & 33.610242 & 82.93 & 24.88 \\
25 & 0.8925 & 33.425282 & 82.77 & 24.69 \\
40 & 0.8924 & 33.122082 & 82.51 & 24.39 \\
55 & 0.8923 & 32.660974 & 82.34 & 24 \\
70 & 0.8922 & 32.070507 & 82.51 & 23.61 \\
85 & 0.8922 & 31.572539 & 82.70 & 23.3 \\
100 & 0.8921 & 31.188947 & 82.73 & 23.02 \\
\hline
\end{tabular}



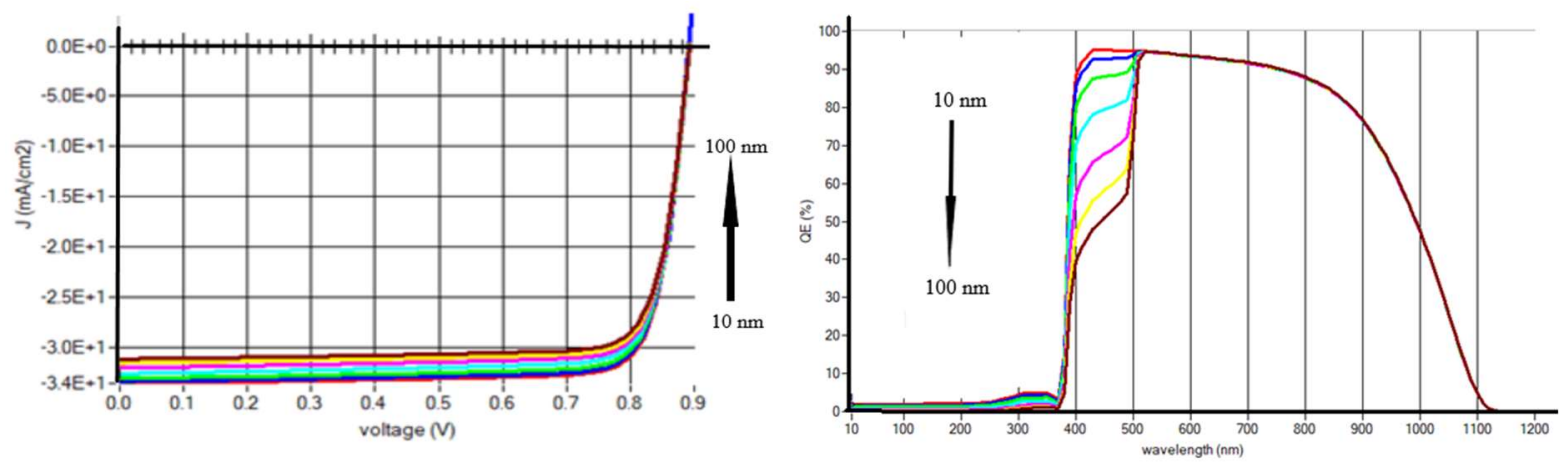

Figure 3: (a) J -V current curves, (b) Quantum efficiency percentage (QE\%) for the cell at different thickness CdS layer, CZTS, ZnO and ITO layer thicknesses are $2400 \mathrm{~nm}, 200 \mathrm{~nm}$, and $280 \mathrm{~nm}$ respectively, $T=300 \mathrm{~K}$

\subsubsection{Effect of $\mathrm{ZnO}$ window layer thickness on the device performance}

The incident radiation should pass through the $\mathrm{ZnO}$ (window) layer. The bandgap of $\mathrm{ZnO}$ is 3.3 $\mathrm{eV}$ (absorbs radiation of $\lambda<300 \mathrm{~nm}, \mathrm{UVC}$ area). Visible and IR radiation are entirely transmitted through the ZnO layer, and CZTS may absorb them [27]. Table 6 shows that changing the $\mathrm{ZnO}$ layer thickness has no effect on device performance characteristics $\left(V_{O C}, J_{S C}, F F\right.$, and $\left.\eta\right)$. Fig. 4 (a) depicts the relationship between device performance efficiency characteristics and ZnO layer thickness. The use of a very thin layer of $\mathrm{ZnO}$ may result in leakage current, while a layer that is too thick may result in a poor carrier separation rate. Finally, $120 \mathrm{~nm}$ is chosen as the optimum and recommended layer. As demonstrated in Fig.4 (b), the QE\% is unaffected by changes in buffer thickness in the range ( $40 \mathrm{~nm}$ to $280 \mathrm{~nm}$ ). This may be ascribed to the window layer sharing a little amount of electron-hole pair creation. Finally, the $120 \mathrm{~nm}$ layer is chosen as the optimal and preferable layer.

Table 6: The effect of window (ZnO) layer thickness on cell efficiency parameter, CZTS, CdS and ITO layer thicknesses are 2400 $\mathrm{nm}, 25 \mathrm{~nm}$, and $280 \mathrm{~nm}$ respectively, $T=300 \mathrm{~K}$

\begin{tabular}{lllll}
\hline Thickness (nm) & Voc $(\mathbf{V})$ & JSC $\left(\mathbf{m A} / \mathbf{c m}^{2}\right)$ & FF & $\boldsymbol{\eta}$ \\
\hline 40 & 0.8925 & 34.044934 & 82.75 & 25.15 \\
80 & 0.8925 & 33.768014 & 82.76 & 24.94 \\
120 & 0.8925 & 33.594461 & 82.77 & 24.82 \\
160 & 0.8924 & 33.490579 & 82.77 & 24.74 \\
200 & 0.8924 & 33.425282 & 82.78 & 24.69 \\
240 & 0.8924 & 33.380924 & 82.78 & 24.66 \\
280 & 0.8924 & 33.34183 & 82.78 & 24.64 \\
\hline
\end{tabular}



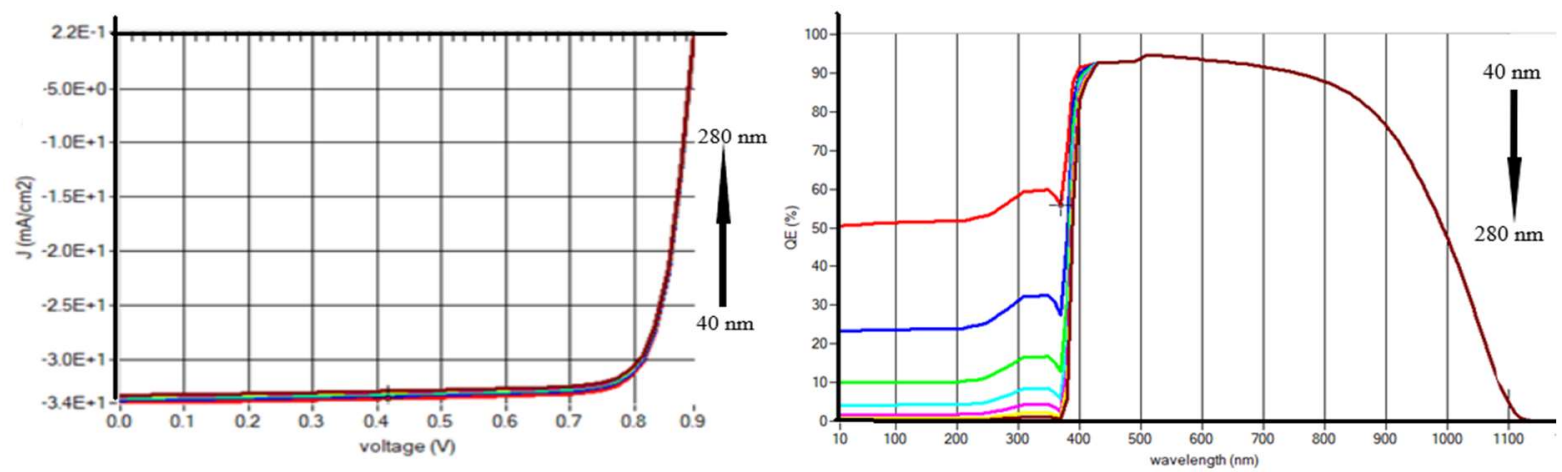

Figure 4: (a) J -V current curves, (b) Quantum efficiency percentage (QE\%) for the cell at different thickness ZnS layer, CZTS, CdS and ITO layer thicknesses are $2400 \mathrm{~nm}, 25 \mathrm{~nm}$, and $280 \mathrm{~nm}$ respectively, $T=300 \mathrm{~K}$

\subsection{Effect of doping concentration on the device performance}

\subsubsection{Effect of CZTS absorber (acceptor) doping concentration on the device performance}

"Fig. 5 (a)" and "Table 7" exhibit the acceptor doping concentration simulation findings. The concentration of the acceptor was adjusted from $1 \times 10^{16} \mathrm{~cm}^{-3}$ to $1 \times 10^{17} \mathrm{~cm}^{-3}$. "Table 7 " shows that when the doping concentration increases, $J_{S C}$ falls while $V_{O C}$ increases. The fundamental reason for this is that when the acceptor carrier concentration rises, so does the device's saturation current, and as a result, $V_{O C}$ rises. $J_{S C}$ diminishes as carrier densities rise, accelerating the recombination process and reducing the likelihood of collecting photon-generated electrons. This is due to an increase in free carrier charge recombination inside the bulk. Longer wavelength photons with lower energy are thoroughly absorbed in the CZTS layer. As a result, the collected conversion efficiency is more reliant on the concentration density's impact. It is obvious from "Table 7" that when the carrier concentration in the absorber layer material increases, $F F$ and $\eta$ rise as well. $\eta$ and FF stay constant until achieving the optimum acceptor carrier concentration, but $V_{O C}$ steadily rises. The higher efficiency in the simulated findings is explained by the combined impact of current density $J_{S C}$ saturation, as well as the quick increase of $V_{O C}$ and FF with acceptor carrier charge concentration $\left(\mathrm{N}_{\mathrm{A}}\right)$. As a result, the best CdTe thin film performance can be attained with $\left(\mathrm{N}_{\mathrm{A}} \sim 5.5 \times 10^{16} \mathrm{~cm}^{-3}\right)$. The following Eq. (12) explains the PN junction model [28]:

$I_{O}=A q n_{i}^{2}\left(\frac{D_{e}}{L_{e} N_{A}}+\frac{D_{h}}{L_{h} N_{D}}\right)$

$I_{O}$ stands for saturation current, $n_{i}$ for intrinsic concentration, $A$ for diode quality factor, $q$ for elementary charge, $T$ for temperature, $k$ for Boltzmann constant, $I_{L}$ for light-generated current, $L$ and $D$ for diffusion length and coefficient, and $N_{D}$ and $N_{A}$ for donor and acceptor charge 
concentrations. The letters $h$ and $e$ stand for holes and electrons, respectively. As the acceptor carrier concentration $N_{A}$ rises, the saturation current $I_{O}$ falls, resulting in an increase in $V_{O C}$ and a drop in $J_{S C}$.

The reason for this is that when the acceptor carrier concentration is high, the recombination process accelerates and reduces the likelihood of electron-hole pair formation, lowering the QE\% of long wavelength photons. Long-wavelength photons will be absorbed profoundly in the absorber (CZTS) layer. The effect of modifications in CZTS acceptor charge carrier concentration $\left(N_{A}\right)$ on solar cell fundamental characteristics was thoroughly examined. The spectrum response of the thin film with CdTe acceptor carrier charge concentration is shown in "Fig. 5(b)" $\left(N_{A}\right)$. The simulated findings show that when the acceptor concentration increases from $1 \mathrm{x} 10^{16} \mathrm{~cm}^{-3}$ to $1 \mathrm{x}$ $10^{17} \mathrm{~cm}^{-3}$, the external quantum efficiency $(Q E)$ decreases. The greater gathering of photons at longer wavelengths can be ascribed to this. The thin-film solar cell has created more electron-hole pairs as a result of the absorption of longer wavelength photons, resulting in an increase in Jsc at low acceptor charge carrier concentration $\left(N_{A}\right)$ (Table 7). The J-V curves show that as the acceptor charge carrier concentration $\left(N_{A}\right)$ of the CdTe layer is increased $\left(N_{A}>1 \times 10^{16} \mathrm{~cm}^{-3}\right), V_{O C}$ rises. This rise implies that the open-circuit voltage $\left(V_{O C}\right)$ of the CdTe layer is highly influenced by the acceptor charge carrier concentration $\left(N_{A}\right)$. The generated electric field in the depletion area is influenced when the acceptor (hole) carrier charge concentration of $\left(N_{A}\right)$ of the CdTe layer is high. As a result, the free charge carrier recombination decreases, increasing the $V_{O C}$. While lowering the CdTe acceptor carrier charge concentration below $1 \times 10^{16} \mathrm{~cm}^{-3}$, causes higher optical losses, which might be due to back contact surface recombination.
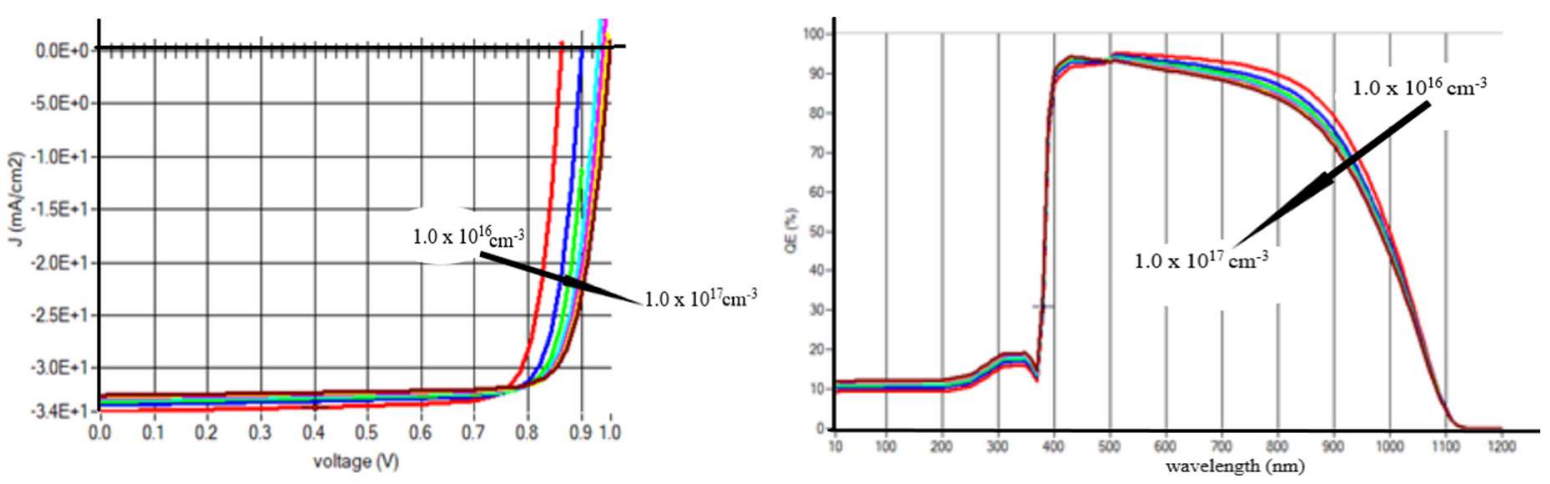

Figure 5: (a) J -V current curves, (b) Quantum efficiency percentage (QE\%) for the cell as a function of CZTS acceptor carrier concentration $\left(N_{A}\right), T=300$ 
Table 7: The effect of absorber (CZTS) carrier concentration $\left(N_{A}\right)$ on cell efficiency parameter, $T=300 \mathrm{~K}$

\begin{tabular}{ccccc}
\hline $\begin{array}{c}\text { Acceptor Concentration, } \\
\left.\text { NA (cm } \mathbf{( c m}^{-3}\right)\end{array}$ & VoC $(\mathbf{V})$ & $\mathbf{J}_{\mathbf{S C}}\left(\mathbf{m A} \mathbf{A} \mathbf{c m}^{\mathbf{2}}\right)$ & FF & $\boldsymbol{\eta}$ \\
\hline $1.0 \times 10^{16}$ & 0.8641 & 34.076207 & 82.35 & 24.25 \\
$2.5 \times 10^{16}$ & 0.9013 & 33.440111 & 82.92 & 24.99 \\
$4.0 \times 10^{16}$ & 0.9195 & 33.120408 & 83.22 & 25.35 \\
$5.5 \times 10^{16}$ & 0.9316 & 32.911432 & 83.34 & 25.55 \\
$7.0 \times 10^{16}$ & 0.9405 & 32.758694 & 83.32 & 25.52 \\
$8.5 \times 10^{16}$ & 0.9477 & 32.639828 & 83.11 & 25.45 \\
$1.0 \times 10^{17}$ & 0.9536 & 32.543485 & 82.75 & 25.38 \\
\hline
\end{tabular}

\subsubsection{Effect of CdS buffer (donor) doping concentration on the device performance}

This section's major goal is to minimize the buffer layer's losses (both optical and electrical). The carrier charge concentration level of the ZnSe layer was altered from $1 \times 10^{17} \mathrm{~cm}^{-3}$ to $1 \times 10^{18} \mathrm{~cm}^{-}$ 3 after that. "Fig. 6 (a)" and "Table 8" illustrate the outcomes of the donor concentration simulation. $J_{S C}$ and $V_{O C}$ are nearly constant as doping concentration increases, as shown in "Table 8."With a rise in doping concentration, the device's conversion efficiency and fill factor have altered marginally. If we increase the doping concentration in a buffer layer beyond the optimal amount $\left(2.5 \times 10^{17} \mathrm{~cm}^{-3}\right)$, the conversion efficiency and fill factor of a device stay steady and begin to drop. As a result, the buffer layer's final ideal concentration value was $2.5 \times 10^{17} \mathrm{~cm}^{-3}$. According to "Fig. 6 (a)," increasing the doping concentration in the buffer layer has no significant effect on the device's operation. As a consequence, it was deduced that a change in buffer layer concentration had no effect on the total output of a photovoltaic device. As the concentration of the buffer layer $\left(N_{D}\right)$ decreases, more incoming photons generated by the CdS layer are absorbed, reducing the number of photons that the absorber (CZTS) layer can absorb. As demonstrated in Fig. 6 (b), absorbed photons form fewer electron-hole pairs, resulting in a lower QE\%. It can be seen that the $\mathrm{QE} \%$ increases as the donor carrier charge concentrations rise. Based on the above, it is recommended to have a high buffer layer donner concentration $\left(N_{D} \approx 2.5 \times 10^{17} \mathrm{~cm}^{-3}\right)$ in the simulation for thin films.

Table 8: The effect of buffer (CdS) carrier concentration (ND) on cell efficiency parameter, $T=300 \mathrm{~K}$

\begin{tabular}{lllll}
\hline $\begin{array}{l}\text { Donor Concentration, } \\
\text { ND }\left(\mathbf{c m}^{-3}\right)\end{array}$ & VoC $(\mathbf{V})$ & $\mathbf{J}_{\text {SC }}\left(\mathbf{m A} \mathbf{A} \mathbf{c m}^{\mathbf{2}}\right)$ & FF & $\boldsymbol{\eta}$ \\
\hline $1.0 \times 10^{17}$ & 0.9135 & 32.911432 & 83.35 & 25.55 \\
$2.5 \times 10^{17}$ & 0.9135 & 32.940552 & 83.68 & 25.68 \\
$4.0 \times 10^{17}$ & 0.9135 & 32.931112 & 83.69 & 25.67 \\
$5.5 \times 10^{17}$ & 0.9134 & 32.872754 & 83.74 & 25.66 \\
$7.0 \times 10^{17}$ & 0.9134 & 32.797653 & 83.79 & 25.60 \\
$8.5 \times 10^{17}$ & 0.9134 & 32.719003 & 83.82 & 25.54 \\
$1.0 \times 10^{18}$ & 0.9134 & 32.64839 & 83.84 & 25.49 \\
\hline
\end{tabular}



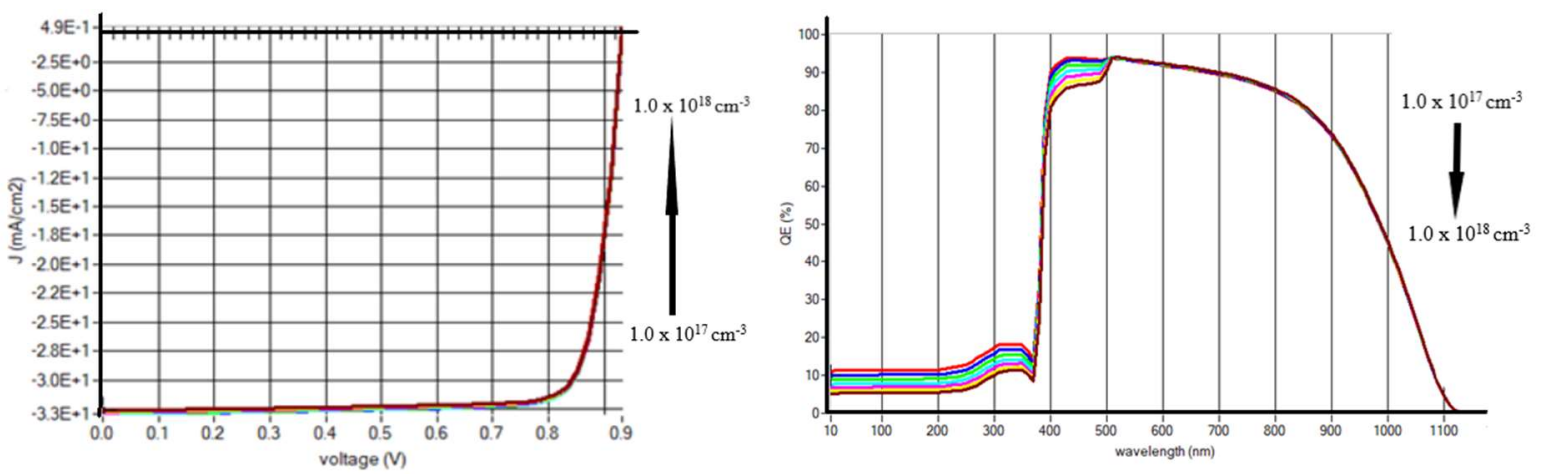

Figure 6: (a) J -V current curves, (b) Quantum efficiency percentage (QE\%) for the cell as a function of CdS donor carrier concentration (ND), $T=300 \mathrm{~K}$

\subsubsection{Effect of $\mathrm{ZnO}$ window doping concentration on the device performance}

Both optical and electrical access is provided by $\mathrm{ZnO}$ (window) layers. Because of its optical bandgap of $3.3 \mathrm{eV}, \mathrm{ZnO}$ was chosen as the window in our scenario because it covers the whole visible wavelength. It can be deduced from Fig. 7 (a and b), as well as Table 9, that the efficiency parameters and $Q E$ percent are unaffected by changes in donor doping concentration in the range of $\left(1.0 \times 10^{18} \mathrm{~cm}^{-3}\right.$ to $\left.1.0 \times 10^{19} \mathrm{~cm}^{-3}\right)$, that the window layer contributes a small amount to electronhole pair generation. The $\mathrm{ZnO}$ donor carrier concentration was measured $\left(\mathrm{N}_{\mathrm{D}} \approx 4 \times 10^{18} \mathrm{~cm}^{-3}\right)$
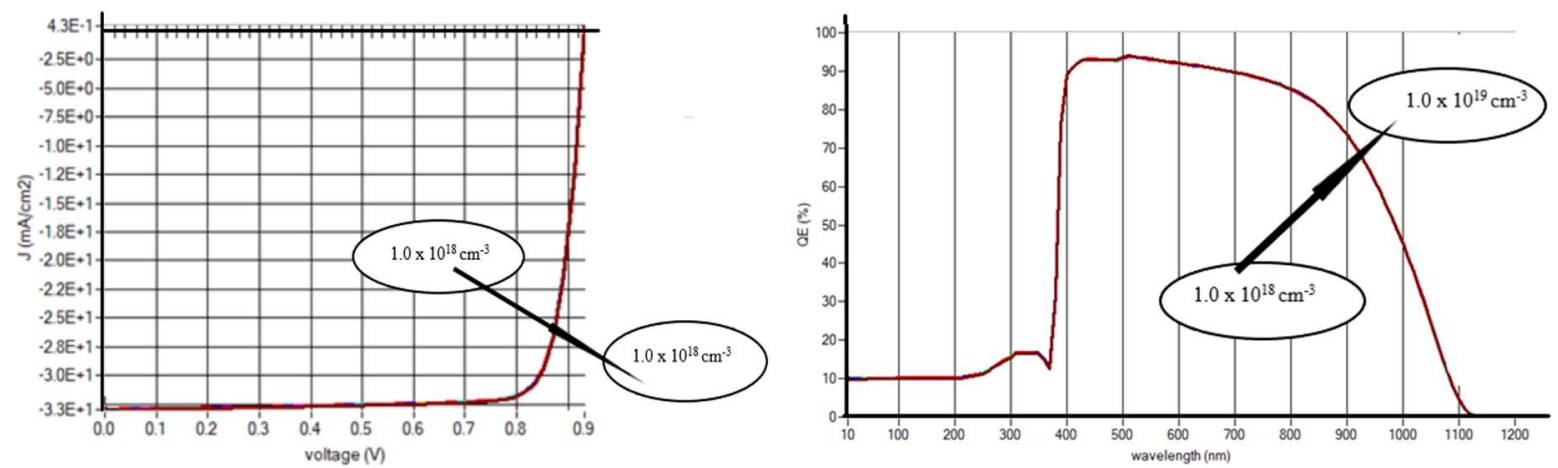

Figure 7: (a) J -V current curves, (b) Quantum efficiency percentage (QE\%) for the cell as a function of ZnO donor carrier concentration $\left(N_{D}\right), T=300 K$

Table 9: The effect of window ( $\mathrm{ZnO}$ ) carrier concentration (ND) on cell efficiency parameter, $T=300 \mathrm{~K}$

\begin{tabular}{lllll}
\hline $\begin{array}{l}\text { Donor Concentration, } \\
\text { ND }\left(\mathbf{c m}^{-\mathbf{3}}\right)\end{array}$ & VoC $(\mathbf{V})$ & $\mathbf{J}_{\text {SC }}\left(\mathbf{m A} \mathbf{A} \mathbf{c m}^{\mathbf{2}}\right)$ & $\mathbf{F F}$ & $\boldsymbol{\eta}$ \\
\hline $1.0 \times 10^{18}$ & 0.9134 & 32.940552 & 83.69 & 25.68 \\
$2.5 \times 10^{18}$ & 0.9134 & 32.956339 & 83.73 & 25.7 \\
$4.0 \times 10^{18}$ & 0.9134 & 32.96436 & 83.76 & 25.72 \\
$5.5 \times 10^{18}$ & 0.9134 & 32.969749 & 83.77 & 25.72 \\
$7.0 \times 10^{18}$ & 0.9134 & 32.973800 & 83.78 & 25.73 \\
$8.5 \times 10^{18}$ & 0.9134 & 32.977041 & 83.79 & 25.74 \\
$1.0 \times 10^{19}$ & 0.9134 & 32.979739 & 83.79 & 25.74 \\
\hline
\end{tabular}




\subsection{Effect of working temperature on the device performance}

In thin-film solar cell applications, the operating temperature plays a key influence on the performance of photovoltaic devices. The photovoltaic panels are placed in an open environment. Heating on solar cells increases as a result of incident light, which has an impact on photovoltaic cell performance. The solar cell panels are functioning at a temperature of above $300 \mathrm{~K}$. The effect of the suggested cell's operating temperature is also explored. The temperature was measured in the range of $280 \mathrm{~K}$ to $400 \mathrm{~K}$ for research reasons. "Fig. 8 (a)" depicts the simulation findings. Temperature has a direct effect on open circuit voltage, which has an impact on total photovoltaic cell performance. Photovoltaic cell performance degrades as the temperature rises. The material carrier concentration, band gaps, electron and hole mobility are all influenced by the greater temperature, resulting in a reduced cell conversion efficiency [29]. Because $V_{O C}$ decreases as temperature rises, the reverse saturation current, $J_{o}$ is temperature dependent. As the temperature rises, the reverse saturation current increases, and this increase in current is the primary source of the drop in $V_{O C}$, as shown in Eq (12) [30]:

$J_{e}=J_{o}\left(e^{\frac{q V_{O C}}{k_{B} T}}-1\right)$ (Eq. 12)

where $J_{e}$ is the photocurrent created by light. The greater operating temperature gives electrons more energy. Because of the greater temperature, these electrons are more likely to recombine with holes before reaching the depletion area. The solar cell efficiency characteristics are shown in "Table 10" which shows that when the temperature rises, the device's conversion efficiency decreases. According to "Eq.12," a rise in operating temperature affects $F F$ and $V_{O C}$, whereas $J_{S C}$ climbs marginally to a stable limit with an increase in operating temperature (no significant effect). This is owing to the temperate-affected drop in band-gap energy [31]. As a result, more farreaching radiation photons will be able to form electron-hole pairs. $V_{O C}$, on the other hand, decreases significantly when the temperature rises. The reverse saturation current $\left(I_{S}\right)$, which is temperature sensitive, is responsible for the reduction in $V_{O C}$ levels with increasing temperature [32]. The inherent carrier concentration [33] is another important component that causes the decrease in $V_{O C}$ with increasing operating temperature. The absorber layer's bandgap is usually rather small. The electron-hole pair recombination may be aided by the narrower bandgaps. The interatomic spacing rises as the amplitude of the atomic vibrations increases owing to increased 
thermal energy [34]. This behavior may be better understood if one thinks that the interatomic spacing grows when the amplitude of the atomic vibrations increases. The linear expansion coefficient of a material is used to quantify this impact. The potential observed by electrons in the material decreases as interatomic separation increases, reducing the energy bandgap. With increasing temperature, the FF percent decreases until it reaches a steady-state temperature limit. Finally, when the temperature rises, the device's conversion efficiency decreases.

Quantum efficiency percent $(\mathrm{QE} \%)$ profiles at different temperature values are shown in Figure 8(b). The QE\% profiles were calculated based on the SCAPS-1D software program. The QE\% profiles show a peak response to illumination wavelength. The QE\% was ranged (80-90\%) in the wavelength range (520-800 $\mathrm{nm})$ and started lowering to $45 \%$ in the range below $(300-520) \mathrm{nm}$. The lowering is due to the recombination and absorption in the absorber and buffer layer. The quantum efficiency was slightly affected with an increase in temperature that falls in the range of $2800-400 \mathrm{~K}$. The QE\% profile shows absorption maxima at $\approx 530 \mathrm{~nm}$, this value is consistent with the input CZTS value $\left(E_{g}=1.45 \mathrm{eV}\right)$. Fig. 8 (b) shows an absorption edge at $800 \mathrm{~nm}$, which can be attributed to vacancy levels in the energy gap, which can be produced by doping. In addition, a minor effect in quantum efficiency with temperature was observed, which can be attributed to the short period in the studied temperature range (280-400), which meant that the range couldn't cause a noticeable effect on the semiconductor construction, and thus only a minor change in quantum efficiency was observed [35].

Table 10: Effect of working temperature on the device performance

\begin{tabular}{lllll}
\hline Temperature $(\mathbf{K})$ & VoC $(\mathbf{V})$ & $\mathbf{J}_{\text {SC }}\left(\mathbf{m A} / \mathbf{c m}^{\mathbf{2}}\right)$ & $\mathbf{F F}$ & $\boldsymbol{\eta}$ \\
\hline 280 & 0.9362 & 32.905463 & 84.16 & 25.93 \\
300 & 0.9315 & 32.964360 & 83.75 & 25.72 \\
320 & 0.9196 & 33.015222 & 83.45 & 25.34 \\
340 & 0.8961 & 33.056706 & 83.17 & 24.64 \\
360 & 0.8633 & 33.089497 & 82.63 & 23.60 \\
380 & 0.8260 & 33.116285 & 81.78 & 22.37 \\
400 & 0.7868 & 33.139151 & 80.74 & 21.05 \\
\hline
\end{tabular}



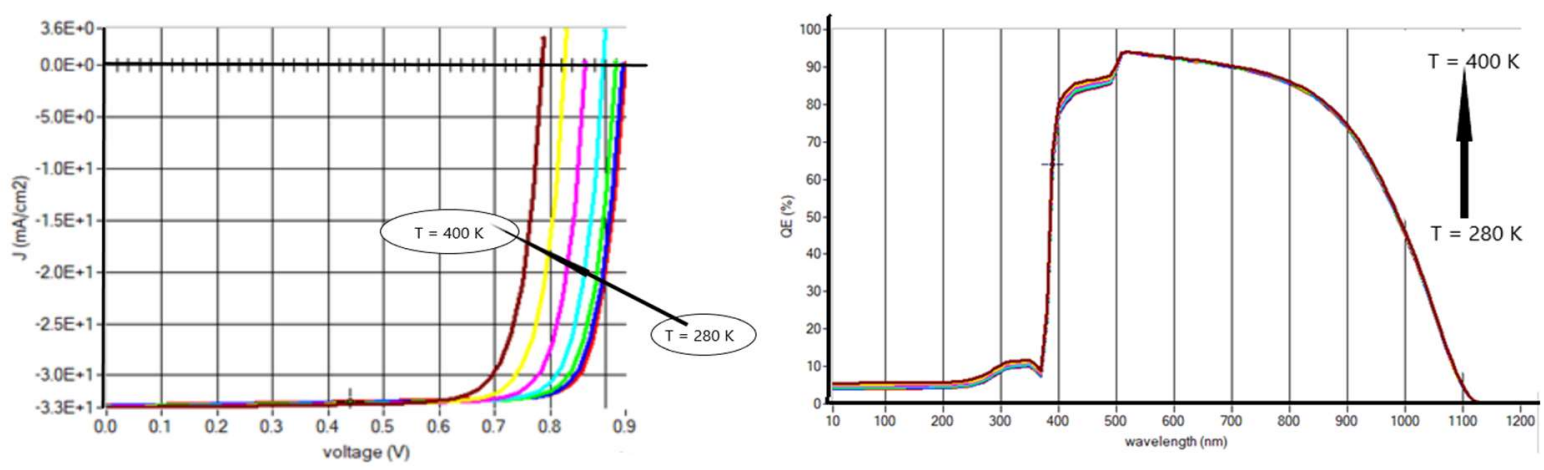

Figure 8: (a) J -V current curves, (b) Quantum efficiency percentage (QE\%) for the cell as a function of temperature

\subsection{Optimization of the $\mathrm{Mo} / \mathrm{CdTe} / \mathrm{ZnSe} / \mathrm{SnO} 2$ thin film -based solar cell}

\subsubsection{J-V characteristics at optimum}

The photovoltaic cell's primary function is to convert light energy into electrical energy. The photovoltaic solar cell is a huge flat diode in the dark, when there is no light, and it generates the exponential J V curve. In dark situations, the cell delivers an extremely low value for current due to minority carriers. Under light irradiation, the solar cell begins to perform, and current flows owing to charge carriers created by incident photons. The cross-over and roll-over of the J-V curves of the $\mathrm{Mo} / \mathrm{CZTS} / \mathrm{CdS} / \mathrm{ZnO} / \mathrm{FTO}$ thin film. The intersection of dark and lit $\mathrm{J}-\mathrm{V}$ curves is known as cross-over. The phenomenon of roll-over occurs when the J-V curve is meshed and current levels of greater voltage are present. The dark and photo J-V curves are depicted in Fig.9. The simulation of SCAPS-1D depends the optimal layer carrier concentration densities in its calculation CZTS $\left(\mathrm{W}=2400 \mathrm{~nm}, \mathrm{~N}_{\mathrm{A}}=5.5 \times 10^{16} \mathrm{~cm}^{-3}\right), \mathrm{CdS}\left(\mathrm{W}=25 \mathrm{~nm}, \mathrm{~N}_{\mathrm{D}}=2.5 \times 10^{17} \mathrm{~cm}^{-3}\right)$, and $\mathrm{ZnO}\left(\mathrm{W}=120 \mathrm{~nm}, \mathrm{~N}_{\mathrm{D}}=4 \times 10^{18} \mathrm{~cm}^{-3}\right)$. The optimum output cell efficiency parameters have been achieved with the conversion efficiency of $25.72 \%$ and $\left(\mathrm{FF} \approx 83.75 \%, \mathrm{~J}_{\mathrm{sc}} \approx 32.96436\right.$ $\mathrm{mA} / \mathrm{cm}^{2}$ and $\left.\mathrm{V}_{\mathrm{oc}} \approx 0.9315 \mathrm{~V}\right)$. The carrier concentration of the absorber layer/buffer layer interface recombination or the absorber/back contact was measured using this advantage [36] 


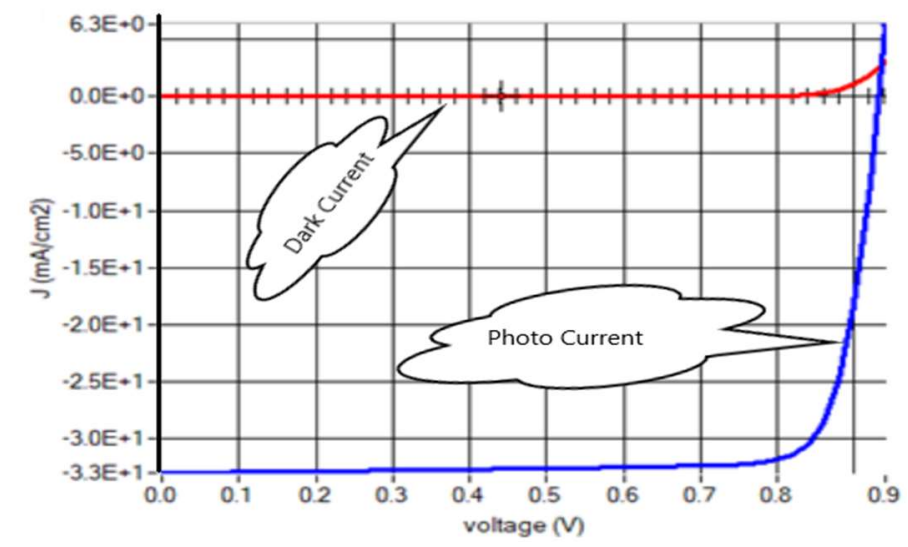

Fig. 9: J -V current curves for optimum thin film (Dark and photo current), at $T=300 \mathrm{~K}$

\subsubsection{Energy band gap at optimum}

Fig. 10 (a and b) depicts the energy band diagram of MO/CZTS/CdS/ZnO/FTO solar cells. For analysis, this energy band diagram was extracted from the SCAPS output. The energy band diagram aids in the explanation of solar cell parameters. The band gap value for incident light photons that is best for most of the light to be absorbed for effective conversion efficiency is more or equal to $1.45 \mathrm{eV}$. One of the most notable criteria impacting thin film performance and current transmission across the heterojunction is band alignment. There is a good band diagram for CZTS as the absorber layer, with $\mathrm{CdS}$ as the buffer layer and $\mathrm{ZnO}$ as the window layer. In Fig. 10 (a) from, 0 to $2.4 \mu \mathrm{m}$ is CZTS absorber layer $\left(E_{g}=1.45\right)$, from $2.4 \mu \mathrm{m}$ to $2.425 \mu \mathrm{m}$ is CdS buffer layer $\left(E_{g}=2.4\right)$, from $2.425 \mu \mathrm{m}$ to $2.545 \mu \mathrm{m}$ is $\mathrm{ZnO}$ window layer $\left(E_{g}=3.3\right)$, and from 2.545 $\mu \mathrm{m}$ to $2.825 \mu \mathrm{m}$ is FTO layer $\left(E_{g}=3.5\right)$. When the conduction band of the absorber layer is higher than the conduction band of the buffer layer, that leads to a "cliff" type band alignment [37]. This is the case of CZTS as the absorber of thin film, as shown in Fig. 10 (b). It can be shown that the absorber, buffer, and window layers have acceptable band alignment. Four recombination zones may be seen in the band diagram. Recombination at the back contact (region R1), bulk (Quasi-Neutral) recombination in the absorber layer (region R2), space charge (region R3), and absorber/buffer interface recombination (region R4) are the four areas. The thin absorber layer will maintain the back-contact close to the depletion zone, resulting in a considerable increase in back contact recombination. Reasonable neutral interface defects for recombination were also evaluated at mid-gap to accommodate recombination at the $\mathrm{CZTS} / \mathrm{CdS}$ and $\mathrm{CdS} / \mathrm{ZnO}$ interfaces [38]. The reflectance of the rear and front contact surfaces was tuned to 0.1 and 0.9 , respectively (Table 3 ). 
Photons that traverse the absorber are reflected by this high reflectivity upon return contact, which improves absorption in the absorber.
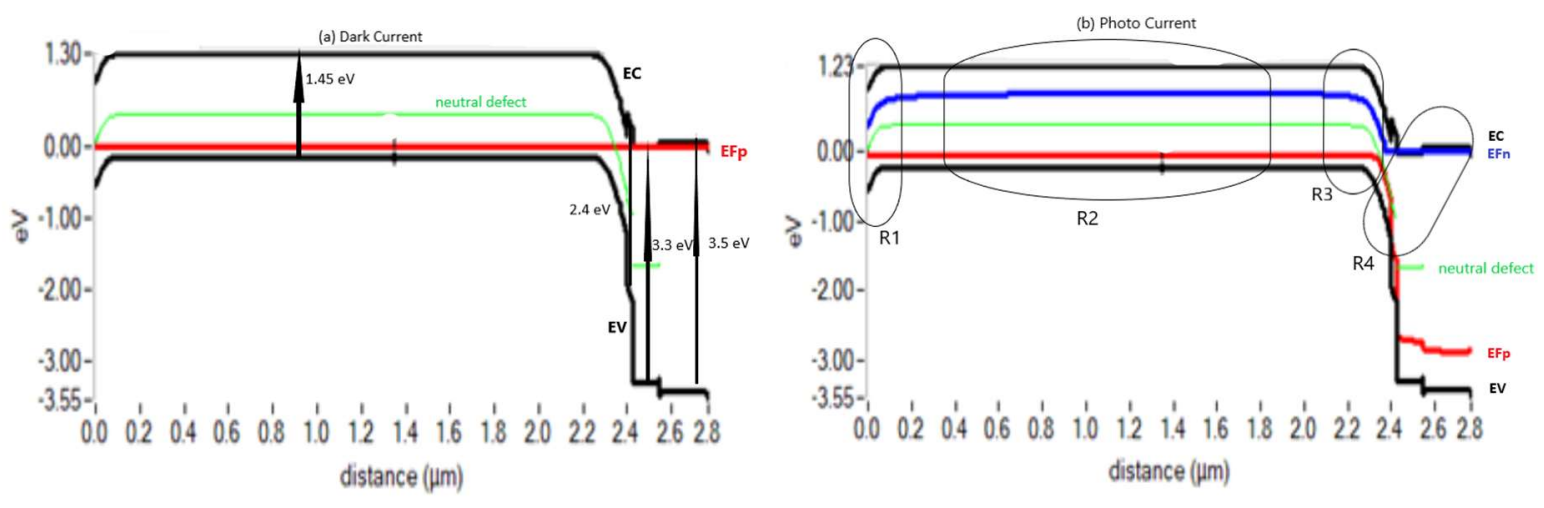

Fig.10: The band Energy diagram at optimum thin film(a) Dark current, (b) Photo Current

\subsection{Comparison the simulation results with experimental thin film-based solar cell}

Tables 11 show the results of our suggested modeling work for thin film MO/CZTS/CdS/ZnO/FTO compared to earlier experimental work.

Table 11: Comparison of functional parameters with experimental result

\begin{tabular}{|c|c|c|c|c|c|c|c|}
\hline Structure & $\mathbf{W}(\mathbf{n m})$ & NA $\left(\mathrm{cm}^{-3}\right)$ & $\mathrm{J}_{\mathrm{SC}}\left(\mathrm{mA} / \mathbf{c m}^{2}\right)$ & $\mathbf{V}_{\text {oc }}(\mathrm{V})$ & FF & $\eta$ & Ref. \\
\hline $\mathrm{CZTS} / \mathrm{CdS} / \mathrm{ZnO}$ & $2400 / 25 / 120$ & $5.5 \times 10^{16}$ & 32.96 & 0.932 & 83.75 & 25.72 & [proposed] \\
\hline $\mathrm{CZTS} / \mathrm{CdS} / \mathrm{ZnO}$ & & & 21.3 & 0.7 & 63 & 9.4 & [39] \\
\hline $\mathrm{CZTS} / \mathrm{CdS} / \mathrm{ZnO}$ & & & 19.5 & 0.661 & 65.8 & 8.4 & [24] \\
\hline $\mathrm{CZTS} / \mathrm{CdS} / \mathrm{ZnO}$ & & & 22 & 0.567 & 58.1 & 7.3 & {$[40,41]$} \\
\hline $\mathrm{CZTS} / \mathrm{CdS} / \mathrm{ZnO}$ & & & 21.8 & 0.614 & 55.5 & 7.1 & [42] \\
\hline $\mathrm{CZTS} / \mathrm{CdS} / \mathrm{ZnO}$ & & & 17.8 & 0.587 & 65 & 6.81 & [43] \\
\hline $\mathrm{CZTS} / \mathrm{CdS} / \mathrm{ZnO}$ & & & 17.9 & 0.610 & 62 & 6.77 & {$[44,45]$} \\
\hline $\mathrm{CZTS} / \mathrm{CdS} / \mathrm{ZnO}$ & & & 19.9 & 0.592 & 57.6 & 6.7 & [42] \\
\hline $\mathrm{CZTS} / \mathrm{CdS} / \mathrm{ZnO}$ & & & 17.6 & 0.584 & 62.89 & 6.44 & [40] \\
\hline $\mathrm{CZTS} / \mathrm{CdS} / \mathrm{ZnO}$ & & & 15.7 & 0.623 & 63.9 & 6.25 & [46] \\
\hline
\end{tabular}

\subsection{Conclusion}

The SCAPS program was used to model and analyze a kesterite MO/CZTS/CdS/ZnO/FTO-based solar cell. Researchers, designers, and engineers will find this work extremely valuable in studying and constructing CZTS-based systems. It should be emphasized that using J-V characteristics to explain the device's behavior is insufficient to fully comprehend the solar cell, which is due to the fact that the solar cell's reaction is also influenced by its internal physical mechanism. Several variables, as well as various alternative simulation situations, must be addressed to improve the 
confidence in the modeling of a solar cell. This work achieved encouraging optimized results with a conversion efficiency of $25.72 \%$ and $\left(\mathrm{FF} \approx 83.75 \%, \mathrm{~J}_{\mathrm{sc}} \approx 32.96436 \mathrm{~mA} / \mathrm{cm}^{2}\right.$ and $\mathrm{V}_{\mathrm{oc}} \approx 0.9315$ V). The findings will provide crucial information for the production of high-efficiency thin-film solar cells. The development of enhanced numerical modeling performance of solar cells plays a vital role, as evidenced by the findings.

Knowlagent: The authors would like to acknowledge the University of Gent, Belgium for providing the SCAPS simulator. Furthermore, we are grateful to Ajman University for supporting this study.

\section{References}

[1] Mariotti, N., Bonomo, M., Fagiolari, L., Barbero, N., Gerbaldi, C., Bella, F., \& Barolo, C. (2020). Recent advances in eco-friendly and cost-effective materials towards sustainable dye-sensitized solar cells. Green Chemistry, 22(21), 7168-7218.

[2] Jacoby, M. (2016). The future of low-cost solar cells. Chem. Eng. News, 94(18), 30-35.

[3] Banu, S., Ahn, S. J., Ahn, S. K., Yoon, K., \& Cho, A. (2016). Fabrication and characterization of cost-efficient CuSbS2 thin film solar cells using hybrid inks. Solar Energy Materials and Solar Cells, 151, 14-23.

[4] Repins, I. L., Romero, M. J., Li, J. V., Wei, S. H., Kuciauskas, D., Jiang, C. S., ... \& Noufi, R. (2012). Kesterite successes, ongoing work, and challenges: a perspective from vacuum deposition. IEEE Journal of Photovoltaics, 3(1), 439-445.

[5] Yadav, M. C., Krishnan, S., Mohammad, F., \& Al-lohedan, H. A. (2019). Fabrication and application of graphenebased composites for indoor air quality and wastewater treatment. In Graphene-Based Nanotechnologies for Energy and Environmental Applications (pp. 359-387). Elsevier.

[6] Zhou, H., Hsu, W. C., Duan, H. S., Bob, B., Yang, W., Song, T. B., ... \& Yang, Y. (2013). CZTS nanocrystals: a promising approach for next generation thin film photovoltaics. Energy \& Environmental Science, 6(10), $2822-2838$.

[7] Xinkun, W., Wei, L., Shuying, C., Yunfeng, L., \& Hongjie, J. (2012). Photoelectric properties of Cu2ZnSnS4 thin films deposited by thermal evaporation. Journal of Semiconductors, 33(2), 022002.

[8] Khattak, Y. H., Baig, F., Ullah, S., Marí, B., Beg, S., \& Ullah, H. (2018). Enhancement of the conversion efficiency of thin film kesterite solar cell. Journal of renewable and sustainable energy, 10(3), 033501.

[9] Hussain, S., Ur Rehman, Z., Mohammad, N., Tahir, M., Shahzada, K., Wali Khan, S., ... \& Gul, A. (2018). Numerical modeling for engineering analysis and designing of optimum support systems for headrace tunnel. Advances in Civil Engineering, 2018.

[10] Haddout, A., Raidou, A., \& Fahoume, M. (2019). A review on the numerical modeling of CdS/CZTS-based solar cells. Applied Physics A, 125(2), 124.

[11] Theraja, B. L. (2008). A textbook of electrical technology. S. Chand Publishing.

[12] Naidu, S. M. (2009). A text book of applied physics. Pearson Education India.

[13] Li, S. S. (1993). Photonic Devices. In Semiconductor Physical Electronics (pp. 327-390). Springer, Boston, MA.

[14] Amin, N., Yamada, A., \& Konagai, M. (2002). Effect of ZnTe and CdZnTe Alloys at the Back Contact of 1- $\mu m-$ Thick CdTe Thin Film Solar Cells. Japanese journal of applied physics, 41(5R), 2834. 
[15] Ullah, H., Marí, B., \& Cui, H. N. (2014). Investigation on the effect of Gallium on the efficiency of CIGS solar cells through dedicated software. In Applied Mechanics and Materials (Vol. 448, pp. 1497-1501). Trans Tech Publications Ltd.

[16] Paudel, N. R., Wieland, K. A., \& Compaan, A. D. (2012). Ultrathin CdS/CdTe solar cells by sputtering. Solar Energy Materials and Solar Cells, 105, 109-112.

[17] Singh, P., \& Ravindra, N. M. (2012). Temperature dependence of solar cell performance-an analysis. Solar energy materials and solar cells, 101, 36-45.

[18] Hegedus, S. S., \& Shafarman, W. N. (2004). Thin-film solar cells: device measurements and analysis. Progress in Photovoltaics: Research and Applications, 12(2-3), 155-176.

[19] Simya, O. K., Mahaboobbatcha, A., \& Balachander, K. (2015). A comparative study on the performance of Kesterite based thin film solar cells using SCAPS simulation program. Superlattices and Microstructures, 82, 248261.

[20] Niemegeers, A., \& Burgelman, M. (1996, May). Numerical modelling of ac-characteristics of CdTe and CIS solar cells. In Conference Record of the Twenty Fifth IEEE Photovoltaic Specialists Conference-1996 (pp. 901-904). IEEE.

[21] Decock, K., Zabierowski, P., \& Burgelman, M. (2012). Modeling metastabilities in chalcopyrite-based thin film solar cells. Journal of Applied Physics, 111(4), 043703.

[22] Burgelman, M., Verschraegen, J., Degrave, S., \& Nollet, P. (2004). Modeling thin-film PV devices. Progress in Photovoltaics: Research and Applications, 12(2-3), 143-153.

[23] Movla, H. (2014). Optimization of the CIGS based thin film solar cells: Numerical simulation and analysis. Optik, 125(1), 67-70.

[24] Shin, B., Gunawan, O., Zhu, Y., Bojarczuk, N. A., Chey, S. J., \& Guha, S. (2013). Thin film solar cell with $8.4 \%$ power conversion efficiency using an earth-abundant Cu2ZnSnS4 absorber. Progress in Photovoltaics: Research and Applications, 21(1), 72-76.

[25] Djinkwi Wanda, M., Ouédraogo, S., Tchoffo, F., Zougmoré, F., \& Ndjaka, J. M. B. (2016). Numerical investigations and analysis of Cu2ZnSnS4 based solar cells by SCAPS-1D. International Journal of Photoenergy, 2016.

[26] Adewoyin, A. D., Olopade, M. A., \& Chendo, M. (2017). Enhancement of the conversion efficiency of Cu2ZnSnS4 thin film solar cell through the optimization of some device parameters. Optik, 133, 122-131.

[27] Kaur, N., Singh, M., Pathak, D., Wagner, T., \& Nunzi, J. M. (2014). Organic materials for photovoltaic applications: Review and mechanism. Synthetic Metals, 190, 20-26.

[28] Luque, A., \& Hegedus, S. (2003). Photovoltaic science and engineering. Chichester: John Wiley \& Sons Ltd.

[29] Hossain, S., Amin, N., Martin, M. A., Aliyu, M. M., Razykov, T., \& Sopian, K. (2011). A NUMERICAL STUDY ON THE PROSPECTS OF HIGH EFFICIENCY ULTRA THIN Zn x Cd 1-x S/CdTe Solar Cell. Chalcogenide Letters, 8(4).

[30] Sha, W. E., Ren, X., Chen, L., \& Choy, W. C. (2015). The efficiency limit of CH3NH3Pbl3 perovskite solar cells. Applied Physics Letters, 106(22), 221104.

[31] Singh, P., \& Ravindra, N. M. (2012). Temperature dependence of solar cell performance-an analysis. Solar energy materials and solar cells, 101, 36-45.

[32] Al-Khazzar, A. A. A. (2016). Behavior of four Solar PV modules with temperature variation. International Journal of Renewable Energy Research (IJRER), 6(3), 1091-1099.

[33] Sproul, A. B., \& Green, M. A. (1993). Intrinsic carrier concentration and minority-carrier mobility of silicon from 77 to 300 K. Journal of Applied Physics, 73(3), 1214-1225. 
[34] Gong, J.-W., Q.-F. Chen, et al. (2006). "Temperature feedback control for improving the stability of a semiconductor-metal-oxide (SMO) gas sensor." IEEE Sensors Journal 6(1): 139-145.

[35] Xiao, B., M. Zhu, et al. (2018). "Optical and electrical properties of vanadium-doped ZnTe crystals grown by the temperature gradient solution method." Optical Materials Express 8(2), 431-439.

[36] Niemegeers, A., \& Burgelman, M. (1997). Effects of the Au/CdTe back contact on IV and CV characteristics of $\mathrm{Au} / \mathrm{CdTe/CdS/TCO}$ solar cells. Journal of applied physics, 81(6), 2881-2886.

[37] Wang, K., Gunawan, O., Todorov, T., Shin, B., Chey, S. J., Bojarczuk, N. A., ... \& Guha, S. (2010). Thermally evaporated Cu 2 ZnSnS 4 solar cells. Applied Physics Letters, 97(14), 143508.

[38] Zhao, W., Zhou, W., \& Miao, X. (2012, March). Numerical simulation of CZTS thin film solar cell. In 20127 th IEEE International Conference on Nano/Micro Engineered and Molecular Systems (NEMS) (pp. 502-505). IEEE.

[39] Tajima, S., Umehara, M., Hasegawa, M., Mise, T., \& Itoh, T. (2017). Cu2ZnSnS4 photovoltaic cell with improved efficiency fabricated by high-temperature annealing after CdS buffer-layer deposition. Progress in Photovoltaics: Research and Applications, 25(1), 14-22.

[40] Patel, M., \& Ray, A. (2012). Enhancement of output performance of Cu2ZnSnS4 thin film solar cells-A numerical simulation approach and comparison to experiments. Physica B: Condensed Matter, 407(21), 4391-4397.

[41] Ahmed, S., Reuter, K. B., Gunawan, O., Guo, L., Romankiw, L. T., \& Deligianni, H. (2012). A high efficiency electrodeposited Cu2ZnSnS4 solar cell. Advanced Energy Materials, 2(2), 253-259.

[42] Tao, J., Liu, J., Chen, L., Cao, H., Meng, X., Zhang, Y., ... \& Chu, J. (2016). 7.1\% efficient co electroplated Cu 2 ZnSnS 4 thin film solar cells with sputtered CdS buffer layers. Green Chemistry, 18(2), 550-557.

[43] Wang, K., Gunawan, O., Todorov, T., Shin, B., Chey, S. J., Bojarczuk, N. A., ... \& Guha, S. (2010). Thermally evaporated Cu 2 ZnSnS 4 solar cells. Applied Physics Letters, 97(14), 143508.

[44] Katagiri, H., Jimbo, K., Maw, W. S., Oishi, K., Yamazaki, M., Araki, H., \& Takeuchi, A. (2009). Development of CZTS-based thin film solar cells. Thin Solid Films, 517(7), 2455-2460.

[45] Chen, S., Walsh, A., Gong, X. G., \& Wei, S. H. (2013). Classification of lattice defects in the kesterite Cu2ZnSnS4 and Cu2ZnSnSe4 earth-abundant solar cell absorbers. Advanced materials, 25(11), 1522-1539.

[46] Yin, L., Cheng, G., Feng, Y., Li, Z., Yang, C., \& Xiao, X. (2015). Limitation factors for the performance of kesterite Cu 2 ZnSnS 4 thin film solar cells studied by defect characterization. Rsc Advances, 5(50), 40369-40374. 